\title{
Cultura: entre a arena de luta e o movimento Hip Hop ${ }^{1}$
}

\section{Culture: between the arena of struggle and the Hip Hop movement}

\author{
Tatiana Aparecida Moreira \\ Universidade Federal de São Carlos \\ $<$ moreira.tatyana@gmail.com>
}

\section{Como citar este artigo (How to cite this article): \\ MOREIRA, Tatiana Aparecida. Cultura: entre a arena de luta e o movimento Hip Hop. Revista Famecos, Porto Alegre, v. 25, n. 2, p. 1-17, maio, junho, julho e agosto de 2018: ID27498. DOI: http://dx.doi.org/10.15448/1980-3729.2018.2.27498.}

\section{RESUMO}

Neste texto, discutiremos o conceito de cultura a partir dos estudos de Stuart Hall $(1989,2001,2003,2004)$ a fim de realçar o caráter plural e, também, político de cultura e de modo a contextualizar o Movimento Hip Hop e seus elementos (MC/rapper, DJ, grafite, break) como culturais e ocupantes, sobretudo, do espaço urbano e da periferia, principalmente, no cenário brasileiro. Além do suporte teórico de Hall, também dialogaremos com outros autores, tais como Foucault (2014, 1995), Gonçalves (2010), Queiroz (2005), Bakhtin (2003), Kellner (2001), Shusterman (1998) e Silva (1998), que trazem contribuições importantes que nos possibilitam evidenciar o Hip Hop como cultura plural. Dos elementos do Hip Hop, daremos destaque à figura do MC (Mestre de Cerimônia) ou rapper, por ser o responsável, em parceria com o DJ, pela produção e por cantar os raps, em cujas letras, comumente, são observados questionamentos e críticas a diversos segmentos da sociedade. Assim, trazemos algumas letras de raps para ilustrar a discussão.

Palavras-chave: Cultura. Movimento Hip Hop. Rapper.

\section{ABSTRACT}

In this text, we will discuss the concept of culture based on Stuart Hall's (1989, 2001, 2003, 2004) studies in order to highlight the plural and political features of culture and to contextualize the Hip Hop Movement and its elements (MC / rapper, DJ, graffiti, break) as cultural and occupant of urban space and periphery, mainly in the Brazilian scenario. In addition to the theoretical support of Hall, we also dialogue with other authors such as Foucault (2014, 1995), Gonçalves (2010), Queiroz (2005), Bakhtin (2003), Kellner (2001), Shusterman (1998) and Silva (1998), which bring important contributions to defense the Hip Hop as a cultural plural. Among the elements of Hip Hop, we will highlight the figure of the MC (Master of Ceremony) or rapper for he being responsible, in partnership with the DJ, for producting and for singing the raps, in whose lyrics, commonly, have criticism of various segments of society. So we bring some raps to illustrate the discussion.

Keywords: Culture. Hip Hop Movement. Rapper.

1 Pesquisa financiada pela Fundação de Amparo à Pesquisa de São Paulo (Fapesp). 


\section{Introdução}

A discussão que realizaremos sobre o conceito de cultura integra a nossa tese de doutorado (Moreira, 2016) e será feita a partir dos estudos de Hall (1989, 2001, 2003, 2004), em que o teórico evidencia o caráter plural e, também, político da cultura. Nesse sentido, "Os três campos da cultura - a ciência, a arte e a vida - só adquirem unidade no indivíduo que os incorpora à sua própria unidade" (Bakhtin, 2003, p. XXXIII). Por isso que, no presente artigo, em meio à arena de luta que representa a palavra cultura, apresentaremos o que o teórico postula a fim de contextualizar o Movimento Hip Hop e seus elementos (MC) rapper, DJ, grafite, break), com o rap (que significa rhythm and poetry, ou seja, ritmo e poesia) inserido nesse meio, como pertencentes a um movimento cultural e presentes, principalmente, no locus urbano, ao mesmo tempo em que produzem e recriam esse espaço.

Além do teórico mencionado, também dialogaremos com outros estudiosos e apresentaremos o que eles propõem tanto em relação à cultura quanto em relação ao universo do Hip Hop. Mas, nos deteremos na figura do $\mathrm{MC} /$ rapper e, de forma breve, os elementos do Hip Hop são, assim, delineados: o MC (Mestre de Cerimônia) ou rapper é quem canta e elabora os raps; o DJ é o responsável pela mixagem de sons e pela produção dos raps também; o grafite é a arte de rua feita pelos grafiteiros e o break é a dança que apresenta coreografias quebradas.

Como"[...] viver significa participar do diálogo: interrogar, ouvir, responder, concordar, etc. Nesse diálogo o homem participa inteiro e com toda a vida:com os olhos, os lábios, as mãos, a alma, o espírito, todo ocorpo, os atos [...]" (Bakhtin, 2003, p.348), teceremos nossas palavras e contrapalavras ${ }^{2}$ em relação à cultura Hip Hop.

\section{Identidades nas alteridades}

Hall (2003) vislumbra perspectivas, tais como culturas como forma de lutas e identidades, que, do nosso ponto de vista, também constituíram as bases do Hip Hop, como as lutas contra a segregação racial e social que visavam à construção de identidades, à liberdade de expressão, ao direito de ir e vir, ao acesso a bens e a serviços, entre outros. $\mathrm{O}$ autor esclarece que a palavra popular pode ter uma gama variada de significados, mas, do ponto de vista do estudioso, nem todos são úteis. Um desses sentidos, segundo Hall (2003), é o que mais corresponderia ao senso comum que veria algo como "popular", porque as massas o escutam, compram, leem, consomem e, de alguma forma,

2 Contrapalavra é um conceito utilizado pelo Círculo de Bakhtin (2003) e representa a resposta à palavra do outro. 
o apreciam demasiadamente. O teórico, por sua vez, prefere trabalhar com uma definição de cultura na qual coloca as relações entre "cultura popular" em uma tensão contínua (de relacionamento, influência e antagonismo) com a cultura dominante. Ou melhor, prefere abordar as intersecções entre ambas.

Assim, para Hall (2003):

O que importa não são os objetos culturais intrínseca ou historicamente determinados, mas o estado do jogo das relações culturais: cruamente falando e de uma forma bem simplificada, o que conta é a luta de classes na cultura ou em torno dela (Hall, 2003, p. 258 , grifo do autor).

Como se observa, essa "[...] luta cultural assume variadas formas: incorporação, distorção, resistência, negociação, recuperação" (Hall, 2003, p. 259). Enfim, é uma arena de luta em constante reelaboração e reacentuação ${ }^{3}$, na qual as pessoas estão envolvidas. Ainda para Hall (2003, p. 263, grifos nossos), a cultura popular"[...] é um dos locais onde a luta a favor ou contra a cultura dos poderosos é engajada; é também o prêmio a ser conquistado ou perdido nessa luta. "É a arena do consentimento e da resistência". Esse ponto de vista dialoga com o que Foucault (1995) aborda sobre a resistência ser constituinte das relações de poder, pois "formas de luta" também estão intrínsecas nas relações de poder, por serem formas de resistência e, outrossim, de exercício da liberdade.

Em entrevista à Heloisa Buarque, quando perguntado sobre diásporas e globalização, Hall afirmou que

[...] a diáspora torna-se um conceito crítico no contexto político da globalização. Dá conta de como é possível que uma cultura sobreviva, estabeleça relações, não se volte para defesas fundamentalistas, e tampouco se perca, tornando-se apenas simulacro e cúmplice do Ocidente. Nestesentidoas diásporassão, sobretudo,umextraordinário laboratório cultural onde as tentativas de sobrevivência e as contranegociações são trabalhadas e experimentadas (Hall, 2013, p. 4).

Podemos indiciar que os elementos do Hip Hop (MC/rapper, DJ, grafite, break), em certa medida, se inserem em um contexto em que as culturas guardam algo que as caracteriza e isso não faz com que elas sejam tais quais eram, por exemplo, antes de seus povos migrarem para outros lugares, pois as culturas estão sempre em movimento, mostrando-se híbridas. Nesse sentido, pode-se falar em identidades, no plural, construídas em relação com outrem, tal qual Hall abordará em outro trabalho, Quem precisa de identidade? (2004).

3 Reacentuação representa um novo tom valorativo atribuído a determinado enunciado, por exemplo (Bakhtin, 2003). 
Para o estudioso, as identidades

[...] não são nunca unificadas: que elas são, na modernidade tardia, cada vez mais fragmentadas e fraturadas; que não são, nunca, singulares, mas multiplamente construídas ao longo de discursos, práticas e posições que podem se cruzar ou ser antagônicos. As identidades estão sujeitas a uma historicizição radical, estando constantemente em processo de mudança e transformação (Hall, 2004, p. 108).

Assim, podemos falar em "identidades", no plural, também no interior do Movimento Hip Hop, tendo em vista que muitos grupos se inserem em uma comunidade, geralmente de periferia, pelo menos no contexto brasileiro;em uma determinada classe social, geralmente a de menos favorecidos economicamente; e pertencentes a um grupo étnico, em sua maioria o de negros. É claro que existem outras variantes, mas, pelo menos nos raps brasileiros, isso pode ser observado, havendo, dessa maneira, a reelaboração e a reacentuação desse movimento cultural nos diferentes países em que está presente e até mesmo em um mesmo país, como o Brasil em que muitos rappers/grupos incorporam à batida tradicional do rap outros sons característicos de suas regiões, bem como questões locais.

No trabalho de Nikito Uqquipega, da região Norte, o regionalismo pode ser observado, por exemplo, no rap"Quantidades Vazias" que mescla alguns sons, como o de mantras, o de gotas de água caindo, o de um despertador/telefone tocando, um coro de vozes femininas, entre outros, que se harmonizam com a letra na qual predominam questionamentos: "[...] quantos vil caçadores estão à espreita por aqui? [...] Quantos já buscaram os segredos da vida e acabaram se perdendo em um oceano de Quantidades Vazias".

O rapper também faz algumas afirmativas: "Você não consome a ganância / Ela é que te consome / Tem que tá esperto / Tem que tá ligeiro / Salve família". Ao final diz: "Realize". Assim, deixa para o interlocutor, o "você", a perspectiva de não só escutar, mas de ter mais atitude para mudar as coisas. O rap de Nikito Uqquipega é só um exemplo das muitas identidades que o rap brasileiro pode assumir, com o locutor fazendo vários diálogos, como este em que faz um trocadilho crítico e irônico com os famosos versos de Shakespeare, em Hamlet, "Ser ou não ser, eis a questão": "Ter e não ser, ser e não ter... Eis a questão...."

Também se podem observar, nesse rap, questionamentos em relação aos que são moradores da região, sobretudo ao fato de as pessoas não se organizarem em prol da coletividade: "O foda é ver que aqui quase ninguém se organiza / quantos pisam nos outros como pisam em formigas? [...]". Depreendese que é preciso a organização das pessoas em entidades de classe a fim de que possam reivindicar e/ou levantar suas contestações. 
Essa questão sobre entidades de classe parece se relacionar com o que Bakhtin discute sobre o nascimento social do homem:

\begin{abstract}
O homem não nasce como um organismo biológico abstrato, mas como fazendeiro ou camponês, burguês ou proletário: isto é o principal. Ele nasce como russo ou francês e, por último, nasce em 1800 ou 1900. Só essa localização social e histórica do homem o torna real e lhe determina o conteúdo da criação e da vida e da cultura. Todas as tentativas de evitar esse segundo nascimento - o social - e deduzir tudo das premissas biológicas de existência do organismo são irremediáveis e estão condenadas ao fracasso: nenhum ato do homem integral, nenhuma formação ideológica concreta (o pensamento, a imagem artística, até o conteúdo de um sonho) pode ser explicada e entendida sem que se incorpore as condições socioeconômicas (Bakhtin, 2009, p. 11).
\end{abstract}

Em síntese, em "Quantidades Vazias", percebe-se que é necessário que as pessoas se organizem de forma mais ampla e plural. Isso também pode estar relacionado à circularidade das relações de poder entre diferentes estratos sociais, se pensarmos, por exemplo, no desmatamento da Amazônia: os que detêm o poder da motosserra, ligados, muitas vezes, ao desmatamento, e os que sofrem com isso, os moradores locais que, em muitos casos, são"expulsos" de suas casas e/ou "trabalham" para os primeiros. As menções à fluidez das identidades no rap ilustram o papel das singularidades na construção de um movimento, 0 Hip Hop, que, ao mesmo tempo em que possibilita a singularidade, unifica os sujeitos em torno de práticas comuns, geralmente as ligadas aos elementos do referido movimento.

Entraremos em outra discussão, mas que se relaciona ao que estamos abordando, cujo foco é o artigo "Que'negro'é esse na cultura popular negra?", de 2001, no qual Stuart Hall discutirá as implicações do deslocamento da distinção erudito/popular, no que chama de pós-moderno global. Inicialmente, menciona que é preciso desconstruir o popular, pois, para Hall, não há como sustentar a ingênua posição do que isso consistiria. E acrescenta: "Eu sei que o que substitui a invisibilidade é um tipo de visibilidade segregada que é cuidadosamente regulada" (Hall, 2001, p. 151).

Com essa citação, podemos fazer um cotejo com o que Foucault (2014) diz sobre os discursos que são dados a ver, na dinâmica das relações de poder. Ou melhor, as formas de discursivização da alteridade também produzem e regulam a maneira como o "outro" será visto e, paralelamente, como será individualizado. Sobre essa questão de como o "outro" pode ser visto, sublinhamos um trecho da apresentação feita pela comissão organizadora do II Congresso Brasileiro de Pesquisadores Negros, realizado em 2010 (Barbosa; Gonçalves e Silva; Silvério, 
2010, p. 11, grifos dos autores), na UFSCar, em que os organizadores do evento salientam que o negro, em vez da expressão "como pode ser visto", prefere a forma como quer ser visto:

É significativo destacar que, ao "negarem" a nomeação imposta de preto e ao se auto-nomearem como negro, afro-brasileiro ou, mais recentemente, como afro-descendente têm, os negros, buscado, por meio de seus intelectuais dentro e fora das universidades, rever, criar, ressignificar sua participação na história passada e presente do Brasil (Barbosa; Gonçalves e Silva; Silvério, 2010, s.p).

No rap "Emiví", de MV Bill, do CD Declaração de guerra, de 2002, o locutor mostra qual discurso é dado a ver, o da exclusão de si e dos seus versus a valorização de si e dos seus, por meio de seu ponto de vista. Além disso, ele trabalha de forma irônica a sua própria "visibilidade segregada", mas resistente, que também pode ser a de seus pares, pois diz que faz "parte do quilombo comandado por Zumbi" (verso 9) e que apesar de ser oriundo do berço da exclusão não se intimidou e resistiu (versos 6 a 8). Estrategicamente, o rapper faz incidir sobre si mesmo o discurso de visibilização, tornando-se, ao mesmo tempo, sujeito e objeto desse discurso, como se observa, no primeiro verso, quando se intitula "pesadelo da elite". Nesse sentido, se alia ao pensamento foucaultiano (2013) sobre a indignidade de se falar pelos outros, como se verifica nos dois penúltimos versos.

Outro ponto a ser sublinhado é a crítica que o locutor faz ao "preto que não quer se assumir" (verso 2), que se alinha à apresentação do II Congresso Brasileiro de Pesquisadores Negros (verso 3), ressignificando a maneira como o negro quer ser visto, como alguém que: não se intimida (verso 7); é resistente (verso 8); se orgulha e tem respeito (verso 10); é inteligente (verso 12); é venenoso (verso 13); destaca-se entre os demais (verso 17); é lutador (verso 19); com missão a cumprir (verso 20). Essa projeção que faz de si remete à exotopia para consigo mesmo ao retratar as suas vivências e "verdades" - que também são as vivências de muitos outros sujeitos -, assim como suas contrapalavras para a elite e ao filhinho de papai (verso 11):

O Pesadelo da elite tá de volta, não morri [...]

Diferente do preto que não quer se assumir

A esse tipo de lavagem cerebral sobrevivi

No meio de uma guerra

Foi onde eu nasci

O berço da exclusão foi onde eu cresci

Não me intimidei

Foi preciso resistir

Faço parte do quilombo comandado por Zumbi [...] 


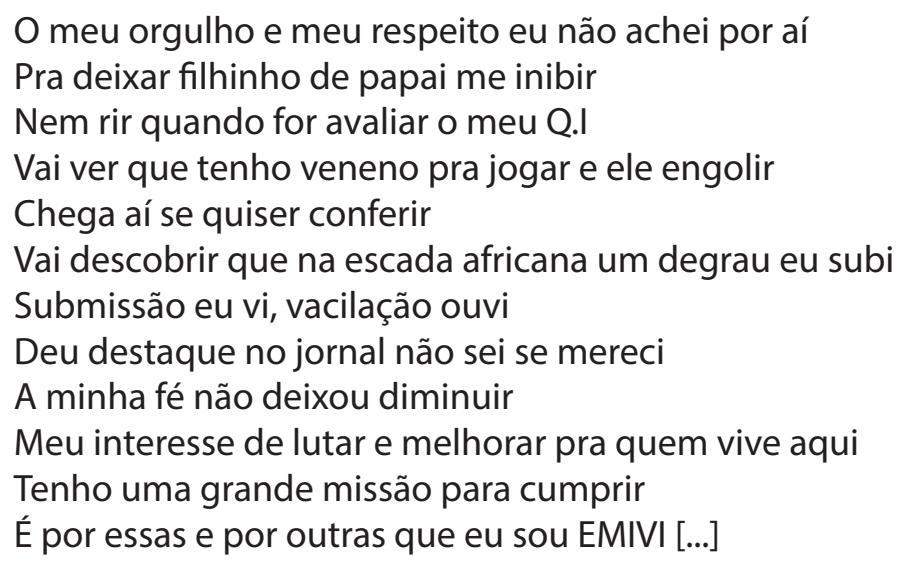

Ainda sobre a questão do popular, Hall (2001) expõe o que, geralmente, se entende como popular, não descartando a possibilidade de estar ligada ao local, com suas experiências, prazeres, memórias e tradições do povo, relacionando tudo isso às práticas e experiências de pessoas comuns. No rap acima, isso pode ser observado, especialmente quando o locutor usa o dêitico "aqui" (verso 19), que remete à partilha de experiências e de vivências locais e comuns.

Aofazer as conexões mencionadas, Hall (2001) estabelece um paralelo com o que Bakhtin (2010) discute sobre o grotesco, o lado baixo, em contraposição à cultura de elite, na relação entre oficial e não oficial, no livro A cultura popular na Idade Média e no Renascimento. Na referida obra, Bakhtin (2010, p. 43) defende que a "[...] a função do grotesco é liberar o homem das formas de necessidade inumana em que se baseiam as ideias dominantes sobre o mundo", uma vez que 0 "[...] grotesco derruba essa necessidade e descobre seu caráter relativo e limitado". Depreende-se que Hall (2001), ao fazer referência à obra bakhtiniana, questiona a visão unilateral e hierarquizada de cultura, como algo que acontece de cima para baixo ou vice-versa, partilhando da ideia de que é preciso avançar na discussão sobre cultura, evitando ficar apenas com dicotomias e, para tal, discute o papel do termo "popular" na cultura popular, que é o de

Fixar a autenticidade de formas populares, enraizando-as em experiências de comunidades populares das quais elas retiram o seu vigor e permitindo-nos vê-las como expressão de uma vida social específica e subalterna, que resiste a ser constantemente transformada em baixa e periférica (Hall, 2001, p. 153).

Mais uma vez, podemos fazer um paralelo com os discursos que são dados a ver na circulação das relações de poder em sua ligação com a resistência e a liberdade, como argumenta Foucault (1995), e que estão presentes nas diferentes esferas do cotidiano, manifestando-se, muitas vezes, de forma 
microfísica e nem sempre aparentes, como nas diferenças econômicas de classe, por exemplo. Avançando um pouco mais na discussão, Hall (2001, p. 153) expõe o caráter dominante da cultura popular na cultura global, defendendo que "Ela está enraizada na experiência popular e, ao mesmo tempo, disponível para expropriação", já que atinge os circuitos de poder e capital, em meio à cena de mercantilização das indústrias. Finaliza essa questão com o seguinte argumento:

Eu quero argumentar que isso é necessário e inevitável, também valendo para a cultura negra popular, que, como todas as culturas populares no mundo moderno, está destinada a ser contraditória, o que ocorre não porque não tenhamos combatido a batalha cultural suficientemente bem (Hall, 2001, p. 153).

Hall (2001, p. 154) argumenta que, da cultura popular negra, mesmo em meio à contradição, até mesmo a de vertente mais comercial, emergem "[...] os elementos de um discurso que é diferente - outras formas de vida, outras tradições de representação". Na mesma direção de Hall, Shusterman (1998, p. 155) salienta que "Como um produto da cultura negra, que é mais oral do que escrita, o rap deve ser escutado e sentido imediatamente em seu dinamismo, para que possa ser apreciado de maneira mais adequada".

Por meio da relação entre dinamismo e imediatismo pode-se depreender que a apreciação de forma mais adequada se relaciona, em alguma medida, ao fato de o rap fazer alusão a situações do cotidiano. Ou seja, os raps são marcados por uma temporalidade e uma espacialidade bem características, como é o caso de muitos raps brasileiros que têm como foco o local, suas relações, em se fazer com e não separadamente.

Ainda sobre a mercantilização ou uma vertente mais comercial da cultura popular negra, isso pode ser notado no trabalho dos Racionais e de MV Bill, já que ambos fazem shows também em casas para "bacanas", esses são assim denominados, geralmente, pelos Racionais. MV Bill também trabalha como ator e se apresenta em TVs abertas, como a Rede Globo. Segundo MV Bill (2014, p. 1): "Tudo que fiz, na mídia, eu fiz porque eu quis, se ficou bom ou não, eu quis fazer. Eu nunca fiquei no ranço do rap de ser antimidiático, essa bandeira eu levantei, eu nunca falei que não ia interagir com "a", "b" ou "c", esse discurso é do [Mano] Brown não é meu. Eu conheço poucas pessoas, como o Brown, que recebem vários convites e recusam [...]". Essa situação ainda se repete, na atualidade, pelos Racionais.

Umexemplofoio Prêmio Multishow 2014, canal por assinatura pertencente ao grupo Globo, no qual o grupo ganhou o prêmio de melhor show do ano, na categoria Superjúri, o show com a Turnê de 25 anos de carreira. O grupo não 
foi receber o prêmio, cabendo à empresária Eliane Dias, esposa de Mano Brown e diretora da produtora Boogie Naipe, a representação para o recebimento do prêmio, já que é uma das responsáveis pela produtora. Um possível motivo que possa explicar a rejeição dos Racionais pela Rede Globo é assim delineado: "A Rede Globo tem a mentalidade do Brasil: racista e preconceituosa. Não adianta passar um pano. Eu tô vendo" (Racionais, 2013, p. 80). Paralelamente a isso, os Racionais têm uma grife, a Fundão Roupas, cujas cores predominantes são o laranja e o preto, comumente usadas nos shows do grupo, com a renda revertida para o herdeiro de um amigo de Mano Brown, Emerson Neguinho, que faleceu há mais de dez anos em um acidente de moto.

Outro exemplo dessa vertente mais comercial seria o rapper Dexter que chegou em um carro de luxo para se apresentar em um evento beneficente em Alphaville, bairro nobre de São Paulo, promovido pelo ex-jogador de futebol, Cafu. Ao ser perguntado por Caco Barcelos, do programa Profissão Repórter da Rede Globo, veiculado no dia 21 de outubro de 2014, sobre qual era o momento do rap, se estava no melhor momento ou se estava um pouco em queda, Dexter respondeu: "Eu sou da opinião que o rap sempre esteve onde tinha que estar. Não é interessante talvez para determinados canais de TV ter o Dexter, ter o Racionais, falando das coisas que a gente fala".

O Dexter, entre uma canção e outra, não deixou de passar a sua mensagem para a elite, quando estava se apresentando: "Não seja preconceituoso com as pessoas, morô! O meu cabelo pode te dizer alguma coisa. A minha cor pode te dizer alguma coisa. Mas o meu caráter e o meu brio também podem te dizer muitas outras coisas. Aprenda a conhecer as pessoas".

Em entrevista conjunta com MV Bill à Revista Fórum (Edição 132, 2014), Dexter assim define o papel do rap e do Hip Hop para a sua vida:"Pode ser 'Ritmo e Poesia', mas eu prefiro 'Revolução Através da Palavra'. A cultura Hip Hop salvou minha vida, mano. Cara, para pra pensar, o rap é o único estilo musical que reúne milhares de pessoas para falar de política e de questões sociais, para colocar o dedo na ferida. O rap tem que incomodar mesmo. Temos que ter uma postura, um comportamento e um compromisso com nosso público [...]" (Mv Bill; Dexter, 2014). Como se observa, há o embate e, ao mesmo tempo, o diálogo na arena de luta na qual a palavra, no caso a circularidade do rap, move-se.

Partilhamos, assim, das ideias de Kellner $(2001$, p. 246) quando este salienta que “[...] resistindo ao significado que exige interpretação, o rap é, muitas vezes, uma máquina de significados que exige interpretação, multiplica sentidos, significações e mensagens políticas". O rap, enquanto máquina multifacetada de significados, destaca-se, como se pôde notar, por apresentar um lado mais comercial que, em alguma medida, pode afetar a recepção e a circulação do 
trabalho dos rappers, uma vez que quanto mais popularidade um grupo/rapper alcança, maior visibilidade ele terá, pois ao aparecer e/ou estar em diferentes meios e mídias poderá ter um público amplo, plural, de variados estratos sociais e de escolaridades distintas.

Esses aspectos se coadunam, de alguma forma, ao que Kellner (2001, p. 9) destaca sobre o papel da cultura da mídia, já que esta “[...] fornece o material necessário que cria as identidades pelas quais os indivíduos se inserem nas sociedades tecnocapitalistas contemporâneas, produzindo uma nova forma de cultura global". Ainda segundo Kellner (2001), ela é constituída: por sistemas de rádio e reprodução de som e respectivos instrumentos de disseminação; de filmes e seus modos de distribuição; pela imprensa; pelo sistema de televisão.

Além disso, caracteriza-se por ser industrial, comercial, visar à grande audiência, explorar a tecnologia mais avançada, seguir o modelo de produção de/para a massa, poder ser vista por aspectos positivos, quando, por exemplo, propicia o avanço de interesses de grupos oprimidos, mas também negativos, quando se constitui em entrave para a democracia ao reproduzir, por exemplo, discursos reacionários (Kellner, 2001). Contudo, não nos aprofundaremos nessas questões, pois não sabemos até que ponto a visibilidade, por exemplo, é regulada/controlada por algum meio ou mecanismo, nem nas de recepção e de circulação, tendo em vista que são questões amplas e complexas e sobre as quais não discutiremos, neste momento.

O que podemos observar é o fato de o rap e também o funk estarem presentes em grandes emissoras de rádio e de televisão, na modalidade aberta, sobretudo em redes nas quais até então não circulavam, ou, se circulavam, eram em menor expressividade, como determinadas variações de rap e de funk, já que nem todas as variações compartilham da "permissão" para circular em certos espaços. Há, desse modo, uma visibilidade que é segregada e regulada por rádios e emissoras, cujo aprofundamento não é nosso foco.

Assim, não é a quantidade que faz, aparentemente, aumentar a visibilidade de certas variantes desses estilos musicais, mas se inclina mais para o fato de a cultura popular urbana, em alguma medida, estar sendo aderida pelas formas de apropriaçãodeuma cultura demassae,consequentemente,pelaindústriacultural que visa, principalmente, ao consumo. Isso se relaciona, de alguma forma, ao que expusemos mais acima a partir das ideias de Kellner (2001). A "popularização", então, teria como foco a venda em larga escala, paralelamente, formas de ser e de estar consideradas do povo, mesmo que, muitas vezes, haja deslocamento de sentido daquilo que pode ser considerado popular. Esse viés comercial e ligado à cultura de massa também é vislumbrado por Shusterman (1998) a respeito do contexto norte-americano e de outros países e situações correlatas: 


\begin{abstract}
O rap não repousa apenas sobre técnicas e as tecnologias da mídia, mas empresta muito de seu conteúdo e deu suas imagens da cultura de massa. Os shows de TV, as vedetes do esporte, os produtos de marcas conhecidas (por exemplo, os tênis Adidas) são frequentemente citados em suas letras, e seus temas musicais ou jingles são muitas vezes incorporados em suas criações. Esses elementos da cultura de massa fornecem o fundo cultural necessário à criação artística e à comunicação numa sociedade em que a tradição da cultura clássica geralmente é ignorada ou julgada pouco atraente, para não dizer alienadora e exclusivista (Shusterman 1998, p. 156).
\end{abstract}

Não seria a dimensão comercial uma possibilidade de resistência da cultura Hip Hop? Um exemplo de lugar de resistência pode ser visto em programas tradicionais no segmento do Hip Hop, como é o caso do Programa Manos e Minas, veiculado pela TV Cultura, desde 2008, e que tem, comumente, uma plateia, além de outras formas de participação pelas redes sociais. 0 programa é, principalmente, voltado para o público da cultura Hip Hop, pois dá destaque às diversas cenas da cultura, mas também veicula outros gêneros musicais, sobretudo os ligados à black music. Além disso, outros segmentos da cultura urbana, principalmente os do contexto de periferia, como a veiculação de produção de roupa de estilistas da periferia, entre outros, também são postos em foco.

Atualmente, o programa é apresentado por Roberta Estrela D'Alva e já teve como apresentadores nomes como Rappin' Hood e Thaíde, pioneiros na cena Hip Hop brasileira. Essa discussão sobre cultura popular negra também se relaciona a questões sobre a etnicidade. Para tanto, trazemos outro texto de Hall, "Novas etnicidades", de 1989, para acrescentar novos argumentos ao que já estamos destacando. Entre outras questões, Hall expõe seu ponto de vista sobre aquilo que compõe a categoria "negro":

[...] istoé, oreconhecimento que o termo"negro"constitui basicamente uma categoria política e cultural construída, que não pode ser fundamentada através de um conjunto de categorias transculturais ou transraciais fixas, as quais, por conseguinte, não estão garantidas a priori. O que estaria posto em jogo aqui é o reconhecimento de uma imensa diversidade e diferenciação da experiência histórica e cultural dos sujeitos negros. Isso inevitavelmente acarreta o enfraquecimento ou o esvaziamento da ideia, segundo a qual, a "raça" ou qualquer outra noção compósita em torno do termo"negro" poderia garantir a eficiência de qualquer prática cultural ou determinar de algum modo o seu valor estético (Hall, 1989, p. 3, grifos do autor).

Nota-se, ao mesmo tempo, a crítica e o posicionamento de Hall a respeito do assunto. Percebe-se que ele defende que o termo "negro" não é algo pré- 
determinado e sobre o qual haja apenas um ponto de vista, de acordo com "categorias transculturais ou transraciais fixas". Segundo o autor, deve-se levar em conta a diversidade, sobretudo histórica e cultural, que constitui os sujeitos. Isso se relaciona ao reconhecimento da variedade das posiçõos subjetivas, das experiências e das identidades que compõem a categoria "negro" (Hall, 1989). Assim, é preciso também, ainda segundo Hall (1989), levar em conta que as dimensões de classe, de gênero, de sexualidade e de etinicidade são importantes para se observar a questão do sujeito negro, a fim de que o conceito essencialista de sujeito negro seja expurgado.

Essas questões se fazem presentes nas narrativas de muitos raps brasileiros. Nesse sentido, Hall (1989, p. 5) defende o conceito de "etnicidade", já que este "[...] reconhece o lugar da história, da linguagem e da cultura na construção da subjetividade e da identidade, bem como o fato de todo discurso estar posto, posicionado e situado, além de admitir que todo conhecimento está contextualizado".

Desse modo, a etnicidade é construída cotidianamente e na relação para com outrem, e não algo dado a priori, por isso Hall (1989, p. 6, grifos do autor) prefere dizer que "[...] estamos todos etnicamente situados, sendo as nossas identidades étnicas cruciais para a nossa percepção subjetiva de quem somos". Ou seja, estamos em um tempo e lugares históricos que nos constituem, via alteridade. Mas isso não quer dizer que estamos previamente determinados, como pôde ser notado, já que a diferença, defendida por Hall, é que nos constitui. Trata-se de uma nova concepção de etnicidade que operaria como uma política cultural que, em vez de suprimir, envolveria a diferença, segundo o estudioso.

Assim, a figura do MC, o Mestre de Cerimônia, se caracterizaria também por essa diferença, uma vez que é aquele que canta e, geralmente, produz os raps, mas, principalmente, é quem vai apresentar e representar não só a si, mas também toda uma comunidade, com seus valores, angústias, alegrias, lutas e tantas outras questões. O MC, de acordo com Queiroz (2005), seria uma espécie de herdeiro/descendente do griot, o contador de histórias na tradição oral africana. Outro estudioso que partilha das ideias de Queiroz é Silva. Para este, "[...] a referência aos griots remete para práticas comuns ao nordeste da África (Gana, Mali) em que uma casta de músicos se responsabiliza pela narrativa da história da sociedade, apoiados normalmente em um instrumento melódico, o kora"(Silva, 1998, p. 37). Nesse sentido, o rapper, na atualidade, seria responsável por contar e relatar histórias que têm como base a vida concreta, por meio de um tipo de narrativa, na sociedade, no caso os raps. Esses, nas diferentes culturas nas quais se fazem presentes, assumem valorações distintas de acordo com o contexto histórico e social em que cada rapper reflete e refrata 
a vida cotidiana, em sociedade. Isso se relaciona ao que o Círculo de Bakhtin (2003) afirma sobre nosso discurso ser repleto de palavras dos outros que são assimiladas, reelaboradas e reacentuadas.

Desse modo, no contexto da diáspora, a cultura negra popular também pode ser assim vista, já que trazia consigo características que lhe eram herdadas de seus povos, mas que assumiram distintas formas, em novos contextos, nos diversos países que os africanos se estabeleceram, o que possibilitou, de acordo com Hall (2001):

Apropriação, incorporação e rearticulação seletivas de ideologias, culturas e instituições europeias, ao lado de um patrimônio cultural africano [...] conduziram a inovações linguísticas na estilização retórica do corpo, a formas de ocupar um espaço social alheio, expressividades potencializadas, estilos de cabelo, posturas, maneiras de andar, de falar, e uma forma de constituir e sustentar a camaradagem e a comunidade, (Hall, 2001, p. 154 - 155).

Por isso que Hall (2001) dirá que é preferível o uso da conjunção "e", em relação às identidades culturais dos migrantes, e não da "ou", que pode remeter à exclusão. Hall ratifica que o fato de se deslocar e, consequentemente, adquirir novas culturas não esgota todas as identidades que as pessoas podem assumir ao longo de suas vidas. Ou seja, essas identidades são complementares, não excludentes e são construídas, como se pode observar, via alteridade, daí a preferência pela conjunção " $e$ " que agrega.

O que acabamos de afirmar parece ser uma ideia afim com a de Gonçalves (2010, p. 22), quando este argumenta que: “Do ponto de vista sociológico, hoje, não temos mais nenhuma dificuldade para compreender que a identidade é construída histórica e socialmente, que é uma construção política". Dessa maneira, e de acordo com Hall, não haveria uma cultura negra popular "pura", tendo em vista o que foi apontado. Também poderíamos dizer que seria difícil encontrar, no contexto da atual sociedade de informação, uma cultura que não sofra influências que lhe são externas, mas que também podem acontecer internamente.

As culturas, assim, estão sempre sofrendo modificações e reacentuações, sendo preciso olhar pela diversidade, como sugere Hall, e não para um viés unilateral. Podemos dizer, desse modo, que o contexto no qual se insere o movimento Hip Hop, outrossim, é diverso e plural. 


\section{Acabamento provisório}

Neste escrito, pôde-se observar que a palavra cultura, no sentido ampliado do termo, conforme discutido a partir dos estudos de Hall (1989, 2001, 2003, 2004), é polissêmica e política, uma vez que é uma arena do embate e do consentimento. Do embate, porque reflete e refrata questões como as apontadas em relação ao contexto diaspórico da cultura negra e do movimento Hip Hop, e do consentimento, tendo em vista que, como no caso dessa mesma cultura negra, há incorporação de práticas por outros povos. Como se percebe, é o novo convivendo no espaço do já-dito.

Assim, em relação ao Hip Hop e seus elementos, em especial à figura do $\mathrm{MC} /$ rapper e do rap, mesmo havendo uma vertente mais comercial, o que se destaca, a partir do que foi exposto, neste artigo, é o empoderamento do que representa ser negro e a discussão de temas relevantes para a sociedade, como relações de classe (entre patrão e empregados; de nível sócio-econômico, entre outras), e de como as relações de poder, na esteira das discussões de Foucault, são operacionalizadas, tanto em nível microfísico, como as que acontecem entre pares, quanto macrofísico, como na relação entre estratos sociais distintos.

Dessa forma, ao se falar em identidades, no plural, procurou-se mostrar que a construção das mesmas, no interior do Hip Hop, é igualmente diversa e plural, visto que é na relação com o outro, no sentido alargado do termo, é que as culturas estão em constante inter-relação.

\section{REFERÊNCIAS}

BAKHTIN, Mikhail. Estética de Criação Verbal. Trad. Paulo Bezerra. 4. ed. São Paulo: Martins Fontes, 2003.

O Freudismo: um esboço crítico. Trad. Paulo Bezerra. São Paulo: Perspectiva, 2009.

A cultura popular na Idade Média e no Renascimento: o contexto de François Rabelais. São Paulo: Hucitec, 2010.

BARBOSA, Lúcia Maria de Assunção; GONÇALVES E SILVA, Petronilha Beatriz; SILVÉRIO, Valter Roberto (orgs.). De preto a afro-descendente: trajetos de pesquisa sobre o negro, cultura negra e relações étnico-raciais no Brasil. São Carlos: EDUFSCar, 2010.

FOUCAULT, Michel. A ordem do discurso: aula inaugural proferida no Collége de France, pronunciada em 2 de dezembro de 1970. 24. ed. São Paulo: Edições Loyola, 2014. 
Microfísica do Poder. 11. ed. Rio de Janeiro: Graal, 2013.

O sujeito e o poder (1984). In: RABINOW, Paul: DREYFUS, Hubert. Michel Foucault: uma trajetória filosófica - para além do estruturalismo e da hermenêutica. Rio de Janeiro: Universitária, 1995.

GONÇALVES, Luiz Alberto Oliveira. De preto a afro-descendente: da cor da pele a categoria científica. In: BARBOSA, Lúcia Maria de Assunção; GONÇALVES E SILVA, Petronilha Beatriz; SILVÉRIO, Valter Roberto (orgs.). De preto a afrodescendente: trajetos de pesquisa sobre o negro, cultura negra e relações étnico-raciais no Brasil. São Carlos: EDUFSCar. 2010.

HALL, Stuart. Notas sobre a desconstrução do popular. In: Da diáspora: Identidades e mediações culturais. Belo Horizonte: UFMG, 2003.

- Quem precisa de identidade? In: SILVA, Tadeu da (org.); HALL, Stuart; WOODWARD, Kathryn. Identidade e diferença: a perspectiva dos estudos culturais 3. ed. Petrópolis, RJ: Vozes, 2004.

Que "negro" é esse na cultura popular negra? Lugar comum, Rio de Janeiro n. 13-14, p. 147-159. 2001. Disponível em: http://uninomade.net/wpcontent/ files_mf $/ 112410120245$ Que\%20negro\%20\%C3\%A9\%20na\%20cultura\%20pop ular\%20negra\%20-\%20Stuart\%20hall.pdf. Acesso em: 20 ago. 2012.

. Novas etnicidades. Trad. David Yann Chaigne. "New ethnicities", em Kobena Mercer (org.), ICA Documents 7: Black Film, British Cinema, Londres: Institute of Contemporary Arts, 1989.

A centralidade da cultura: notas sobre as revoluções culturais do nosso tempo. Educação \& Realidade, Porto Alegre, v. 22, n. 2, p. 15-46, jul./dez. 1997. Disponível em: http://www.gpef.fe.usp.br/teses/agenda_2011_02.pdf. Acesso em: 22 out. 2008.

. Entrevista com JB Stuart Hall. [15 de setembro, 2013]. Rio de Janeiro: Jornal do Brasil. Entrevista concedida a Heloisa Buarque de Hollanda. Disponível em: http://www.heloisabuarquedehollanda.com.br/entrevista-jb-stuart-hall/ Acesso em: 11 out. 2013.

KELLNER, Douglas. A cultura da mídia - estudos culturais: identidade e política entre o moderno e o pós-moderno. Trad. Ivone Castilho Benedetti. Bauru, SP: EDUSC, 2001.

MOREIRA, Tatiana Aparecida. Discursividade, poder e autoria em raps brasileiros e portugueses: arenas entre a arte e a vida. 2016. 297f. Tese (Doutorado em Linguística). Universidade Federal de São Carlos. São Carlos, 2016. 
MV BILL; DEXTER. MV Bill e Dexter minam o campo periférico [31 de janeiro, 2014]. Revista Fórum. Entrevista concedida a Igor Carvalho. Disponível em: http:// www.revistaforum.com.br/blog/2014/01/mv-bill-e-dexter-minam-o-campoperiferico/. Acesso em: 10 abr. 2015.

MV BILL. Emiví. In: Declaração de guerra. Rio de Janeiro: Natasha Records e BMG, 2002. 1 CD.

QUEIROZ, Amarino Oliveira de. Griots, cantadores e rappers: do fundamento do verbo às performances da palavra. In: DUARTE, Zileide (org.). Áfricas de África. Recife: Programa de Pós-graduação em Letras/UFPE, 2005.

RACIONAIS MC's. Os quatro pretos mais perigosos do Brasil. Rolling Stone Brasil, ed. 86, p. 79-86, Reportagem de André Caramante, nov. 2013.

SILVA, José Carlos Gomes. Rap na cidade de São Paulo: música, etnicidadee experiência urbana. 1998. 285 f. Tese (Doutorado em Ciências Sociais) - Programa de PósGraduação do Departamento de Ciências Sociais do Instituto de Filosofia e Ciências Humanas da Universidade Estadual de Campinas, Campinas, 1998.

. Arte e Educação: A Experiência do Movimento Hip Hop Paulistano. In: ANDRADE, Elaine Nunes (org.). Rap e educação, rap é educação. São Paulo: Summus, 1999.

SHUSTERMAN, Richard. Vivendo a arte: o pensamento pragmatista e a estética popular. São Paulo: Ed. 34, 1998.

UQQUIPEGA, Nikito. Rap Região Norte. Facebook, 2015. Disponível em: https://www. facebook.com/groups/178548648964927/. Acesso em: 10 dez. 2015.

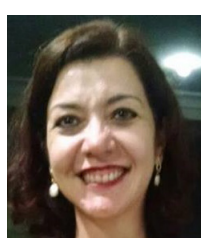

Dados da autora:

Tatiana Aparecida Moreira | moreira.tatyana@gmail.com

Instituto Federal do Espírito Santo (IFES)

Doutora em Linguística pela Universidade Federal de São Carlos (UFSCar). Professora do Instituto Federal do Espírito Santo - IFES

Endereço da autora:

Rua Elizabeth Minete Perim, s/n, São Rafae

29375-000 - Venda Nova do Imigrante (ES) - Brasil 